\title{
REFLEXÕES SOBRE QUESTÕES RECENTES RELACIONADAS COM A DIGNIDADE HUMANA E O FINAL DA VIDA ${ }^{1}$
}

\author{
REFLECTIONS ABOUT RECENT QUESTIONS RELATIONAL TO HUMAN DIGNITY AND THE END \\ OF LIFE
}

Paola Bilancia ${ }^{2}$

\begin{abstract}
Resumo: $O$ ensaio analisa as principais e mais recentes questões relacionadas à dignidade humana e ao fim da vida nos sistemas constitucionais italiano e europeu. A autora estuda a cronologia das evoluções doutrinárias e jurisprudenciais em matéria de eutanásia (passiva e ativa) e suicídio assistido no sistema multinível de proteção de direitos. As questões são contextualizadas pela sua relevância constitucional. A autora analisa a legislação atual e as recentes reformas que regulamentam o fim da vida. Por fim, a autora analisa a decisão da Corte Constitucional no "caso Cappato" e as potenciais evoluções que esse caso promoverá no sistema constitucional italiano quanto à legitimação de algumas formas de "eutanásia ativa".
\end{abstract}

Palavras-chave: Fim da vida. Dignidade humana. Suicídio assistido. Eutanásia.

\begin{abstract}
The essay analyses the main new issues connected to human dignity and end of life in the Italian and European constitutional systems. The Author studies the chronology of doctrinal and jurisprudential evolutions on the matters of euthanasia (passive and active) and assisted suicide in the multilevel system of protection of rights. The issues are contextualized in the relevant constitutional framework. The Author analyses the current legislation and recent reforms regulating end of life. Lastly, the Author analyses the decision of the Constitutional Court in the "Cappato case" and the potential evolutions that it will promote in the Italian constitutional system with regard to the legitimization of some forms of "active euthanasia".
\end{abstract}

Keywords: End of life. Human dignity. Assisted suicide. Eutanásia.

Recebido em 6 de fevereiro de 2020

Aceito em 23 de abril de 2020

\section{Notas sobre a evolução do debate constitucional sobre o fim da vida nos ordenamentos constitucionais}

Graças ao progresso biomédico e biotecnológico, hoje é possível prolongar a vida através de tratamento de muitas doenças que antes eram mortais, inclusive recorrendo a tecnologias que permitem manter as funções vitais de maneira artificial. ${ }^{3}$ Estas possibilidades que oferecem a ciência permitem sobreviver em condições até mesmo muito críticas: sobreviver conectados a máquinas em

\footnotetext{
Tradução do espanhol para o português por Barbara Welter e Carlos L. Strapazzon.

Bárbara Welter: Mestre em Direito pela Universidade do Oeste de Santa Catarina; Advogada; https://orcid.org/0000-00026381-8286; barbara.mwelter@gmail.com

Carlos L. Strapazzon: Doutor e Mestre em Direito pela Universidade Federal de Santa Catarina; Professor no Programa de Pós-graduação em Direito da Universidade do Oeste de Santa Catarina e da Universidade Positivo; https://orcid.org/00000001-6595-548X; strapazzon.carlos.luiz@gmail.com

2 Professora de Direito Constitucional no Departamento de Estudos Internacionais, Jurídicos e Histórico-políticos da Faculdade de Ciência Política, Econômica e Social da Universidade de Estudos de Milão, Itália; paola.bilancia@unimi.it

3 Sobre as biotecnologias e sobre os perfis constitucionais relacionados, ver: A. BALDASSARRE, Le biotecnologie e il diritto costituzionale, en M. Volpi (coord), Le biotecnologie: certezze e interrogativi, Bologna, Il Mulino, 2001.
} 
condições irreversíveis, ou somente graças à alimentação e hidratação, mas sem capacidade cognitiva, ou ainda sobreviver somente com capacidade cognitiva mas sem nenhuma capacidade fisiológica. Vários ordenamentos nacionais permitem formas de eutanásia (ativa ou passiva), enquanto que a maioria a proíbem expressamente ao considerar como comportamentos penalmente relevantes a incitação e a assistência ao suicídio. ${ }^{4}$

Às vezes as Constituições nacionais regulam expressamente o direito à vida, circunstância que permite (ou melhor dizer, impõe) ao legislador e eventualmente em seu defeito, à justiça constitucional interpretar o conceito de "vida" (com referência à definição do começo da mesma, como é o caso da legislação relativa ao aborto ou bem ao fim da vida, assim como o testamento vital ou a eutanásia). ${ }^{5} \mathrm{O}$ direito à vida está expressamente reconhecido pelo artigo $2^{\circ}$ do Convênio Europeu de Direitos Humanos. Enquanto que, por exemplo, na Constituição Italiana o direito à vida não se contempla expressamente, pelo que foi reconhecido no âmbito dos direitos invioláveis da pessoa pela via jurisprudencial (através de uma interpretação aberta do artigo $2^{\circ}$ da Constituição Italiana $)^{6}$ in primis nas decisões relativas à legislação sobre o aborto, em equilíbrio com a relação ao direito à saúde e ao princípio de autodeterminação da pessoa. ${ }^{7}$

Para as decisões referentes ao final da vida, a questão é ainda mais complexa: pode-se entender facilmente como a ideia de se manter vivo artificialmente pode, para alguns não coincidir com a concepção ideal de uma vida que, todavia, merece a pena ser vivida. Naturalmente, estes pensamentos também estão entrelaçados com considerações pessoais ético-religiosas. ${ }^{8}$ Não é por acaso que a atenção do debate político desenvolvido desde meados do século passado se concentrou em tais questões éticas, coincidindo ademais com as possibilidades que oferecem o progresso científico médico que prolongou a vida com formas de supersobrevivência ainda que inadequadas ao conceito de vida e de dignidade humana. ${ }^{9}$

\footnotetext{
4 Para uma análise comparativa da legalidade (ou ilegalidade) da eutanásia dos diferentes ordenamentos, ver: J. GRIFFITHS, H. WEYERS, M. ADAMS, Euthanasia and Law in Europe, Oxford, Hart, 2008; N. FERREIRA, Revisiting euthanasia: a comparative analysis of a right to die in dignity, enZERP Discussion Papers, n. 4, 2005; H. SILVING, Euthanasia: a study in comparative criminal law, University of Pennsylvania Law Review, vol. 103, 1954; M. D. SAYID, Euthanasia: A comparison of the criminal laws of Germany, Switzerland and the United States, Boston College International \& Comparative Law Review, vol. 6, n. 2, 1983; H. SCHNEIDER, Euthanasia: a comparative examination of its place within the scope of the criminal law, Criminologica, vol. 7, n. 2, 1969.

5 Ver: M. MANNES, Euthanasia vs. the right to life, Baylor Law Review, vol. 27, n. 1, 1975; E. PALOMBI, Istigazione o aiuto al suicidio, Enciclopedia del diritto,XXII, Milano, Giuffrè, 1972.

6 A respeito ver: F. MODUGNO, I "nuovi diritti" nella giurisprudenza costituzionale, Torino, Giappichelli, 1995; A. BARBERA, Commento all'art. 2, en G. Branca (coord), Commentario della Costituzione, Bologna-Roma, Zanichelli, 1975.

7 Sobre o direito à vida no ordenamento constitucional italiano ver: S. CURRERI, Lezioni sui diritti fondamentali, Milano, Franco Angeli, 2018, 209 ss.; R. BOTTA, Il diritto alla vita nell'ordinamento giuridico italiano, en Il diritto ecclesiastico, n. 2 , 1992.

8 Sobre as questões constitucionais e morais que são subjacentes sobre o tema do fim da vida, consulta-se: A. PATRONI GRIFFI, Le regole della bioetica tra legislatore e giudici, Napoli, Editoriale Scientifica, 2016; E. CASTORINA, Concezioni bioetiche e principi costituzionali: il problema delle scelte di fine-vita, enTeoria del diritto e dello Stato, nn. 2-3, 2009; F. LOSURDO, L'ultima scelta. dogmatiche dell'autodeterminazione fine vita, en Koreuropa, n. 12, 2018; T. O. MARTIN, Euthanasia and modern morality (their moral implications), en Jurist, vol. 10, n. 4, 1950.

9 Sobre a relação entre os valores da vida e a dignidade humana, ver: A. RUGGERI, Dignità versus vita?, en Rivista AIC, n. 1, 2011.
} 
O conceito de dignidade humana é, pois, não somente comum à tradição jurídica e filosófica europeia (e ocidental), senão também universal. ${ }^{10}$ Queremos recordar aqui a Constituição Federal Brasileira de 1988, que considera a dignidade humana como um limite para o Estado e para as comunidades. ${ }^{11}$ Por essa razão, considerando os problemas sobre o final da vida, o conceito de dignidade humana se utiliza frequentemente como um conceito "guarda-chuva" para todos os direitos fundamentais que protegem a vida humana e as escolhas do indivíduo em referência à forma em que a vida deve desenvolver-se ou terminar. ${ }^{12}$ A partir desta perspectiva, a dignidade humana também significa inevitavelmente a dignidade da morte. ${ }^{13}$

Nossa Constituição (Italiana) prescreve sobre o direito à saúde que, "ninguém pode ser obrigado a um determinado tratamento de saúde se não por disposição legal. A lei não pode em nenhum caso vulnerabilizar os limites impostos pelo respeito da vida humana." É por isso que a recusa de um tratamento se engloba neste âmbito e se no passado os tratamentos se aplicavam pelo médico "em ciência e consciência", hoje o paciente deve estar plenamente informado sobre suas condições de saúde e dos tratamentos a seguir, decidindo inclusive se aceita ou não os tratamentos que podem lhe salvar a vida, exceto para o caso de tratamentos de saúde obrigatórios previstos pela lei. ${ }^{14}$

Não é por acaso que não existe obrigação de viver ou de cuidar a si mesmo, senão através da plena autodeterminação e depois de haver recebido toda a informação necessária (em cumprimento à chamada obrigação de consentimento informado) podem recursar os tratamentos necessários para sobreviver. ${ }^{15}$ A responsabilidade moral atinge exclusivamente os direitos do interessado. De acordo com isto, a ratio do chamado "tratamento vital" segundo o qual o médico, utilizando os meios apropriados ao estado do paciente, deve se esforçar em aliviar o sofrimento, incluindo nos casos de recusa ou renovação do consentimento para receber o tratamento médico indicado pelo especialista. ${ }^{16}$ Com este fim, sempre se garante um tratamento adequado contra a dor com a participação do médico geral e a prestação de cuidados paliativos aos que têm referência na Lei n ${ }^{\circ} 38$, de 15 de março de 2010 .

\footnotetext{
${ }_{10}$ Considere, para todos, os conhecidos casos do "lançamento de anões" francês (conhecido também em inglês com a expressão dwarf-tossing) e do "circuito láser" alemão (também conhecido em inglês com a expressão "lasertag"). Cfr.: Comité Europeo de Derechos Humanos, Comunicación No 854/1999: Francia. 26/7/2002. CCPR/C/75/D/854/1999; CGUE, caso Omega, C-36/02.

${ }^{11}$ Consulta-se sobre o tema I. W. SARLET, Dignidade da pessoa humana e direitos fundamentais na Constituição Federal de 1988 , X ed., Porto Alegre, Livraria do Advogado, 2019.

12 Ver: J. LUTHER, The judge's power over life and death, en Corti supreme e salute, n. 2, 2018, 3.

13 Neste sentido ver: H. KÜNG, Della dignità del morire, Milano, Rizzoli, 1996.

14 Sobre a vontade da pessoa e os tratamentos de saúde, ver: F. G. PIZZETTI, Alle frontiere della vita. Il testamento biologico tra valori costituzionali e promozione della persona, Milano, Giuffrè, 2008, 69 ss. Sobre a leitura do artigo 32 da Constituição, ver: D. MORANA, La salute nella Costituzione italiana. Lezioni, II ed., Torino, Giappichelli, 2015; A. SIMONCINI, E. LONGO, Art. 32, en R. Bifulco, A. Celotto, M. Olivetti (Coords.), Commentario alla Costituzione, Torino, Utet, 2006; B. CARAVITA, La disciplina costituzionale della salute, in Diritto e società, n. 1, 1984; M. LUCIANI, Il diritto costituzionale alla salute, en Diritto e società, n. 4, 1980; S. PANUNZIO, Trattamenti sanitari obbligatori e Costituzione, en Diritto e società, n. 4, 1979.

15 Ver: C. TRIPODINA, Articolo 32, en S. Bartole, R. Bin (coord), Commentario breve alla Costituzione, Padova, CEDAM, 2008, 328 ss.

${ }^{16}$ Neste sentido, F. G. PIZZETTI, Alle frontiere della vita. Il testamento biologico tra valori costituzionali e promozione della persona, cit., passim.
} 
É neste contexto que deve estar centralizado o debate sobre a eutanásia. ${ }^{17}$

A eutanásia é um ato do médico destinado a causar a morte do paciente em razão de sua explícita vontade. O tema da eutanásia é percebido em todas as partes como uma questão delicada e que exige uma atenção extrema na eleição de uma terminologia, as formas e os contextos para tratála. Particularmente, na Itália existe certa desconfiança nas linhas de demarcação claras destinadas a apoiar o direito a uma boa morte. Entretanto, os casos de Piergiorgio Welby, Giovanni Nuvoli, Eluana Englaro, Fabiano Antonian ("DJ Fabo") revelaram a inadequação de certa legislação italiana, dando lugar aqui a uma onda de reações que criaram um debate sem precedentes sobre a legalidade e o valor legal do testamento vital em relação à eutanásia. ${ }^{18}$

A evolução da jurisprudência chegou a terrenos imprevisíveis, outorgando legitimidade, em alguns casos, à chamada eutanásia "passiva", isto é, à suposição dos tratamentos médicos necessários para manter a vida a um paciente, especialmente através do debate sobre o conhecido caso de Piergiorgio Welby. ${ }^{19}$

Em contrapartida, a assim chamada eutanásia "ativa" está proibida na Itália, onde se equipara ao suicídio (caso que não vem sancionado nem sequer no sentido de tentativa de suicídio) ${ }^{20}$ e não se distingue da disciplina pena por assassinato se é levada à cabo por terceiros, e onde os casos de ajuda e incitação ao suicídio se consideram condutas delitivas, apesar de que o debate sobre o tema é cada vez mais amplo no que se refere à autodeterminação e à decisão autônoma de uma boa morte.

\section{0 direito à vida no sistema de proteção multinível dos direitos}

A proteção dos direitos fundamentais, entretanto, não se limita ao nosso sistema jurídico (incluindo o que se refere sobre a legitimidade constitucional das leis), senão que está entrelaçado com a proteção do Direito Internacional (Convênio Europeu de Direitos Humanos) ${ }^{21}$ e supranacional (Tribunal de Justiça da União Europeia), assim como com instrumentos jurídicos internacionais

\footnotetext{
17 Sobre este tema ver: D. NERI, Eutanasia. Valori, scelte morali, dignità delle persone, Roma-Bari, Laterza, 1995.

${ }^{18}$ Ver, mais recentemente, G. MANIACI, Perché abbiamo un diritto costituzionalmente garantito all'eutanasia e al suicidio assistito, en Rivista AIC, n. 1, 2019.

19 Sobre o tema pode ser consultado, A. PIZZORUSSO, Il caso Welby: il divieto di non liquet, en Quaderni costituzionali, n. 2, 2007; P. VERONESI, Sul diritto a rifiutare le cure salvavita prima e dopo il caso "Welby" - una replica, en Studium iuris, n. 10, 2008.

20 Tanto é assim que se afirma de maneira compartilhada, que o suicídio é uma "conduta neutra" no sistema jurídico italiano. Pode ser consultado sobre o tema, S. CANESTRARI, Biodiritto (diritto penale), en Enciclopedia del diritto, Annali VIII, Milano, Giuffrè, 2015; P. VERONESI, Uno statuto costituzionale del corpo, en S. Canestrari (coord), Trattato di bio diritto. Il governo del corpo, Milano, Giuffrè, 2011., 150 ss.

${ }^{21}$ Enquanto a jurisprudência do TEDH sobre questões relativas ao final da vida, ver: U. ADAMO, Il diritto convenzionale in relazione al fine vita (eutanasia, suicidio medicalmente assistito e interruzione di trattamenti sanitari prodotti di una ostinazione irragionevole). Un'analisi giurisprudenziale sulla tutela delle persone vulnerabili, en Rivista AIC, n. 2, 2016.
} 
específicos para a proteção dos direitos humanos no marco dos denominados "biodireitos" (neste caso, o Convênio de Oviedo). ${ }^{22}$

O Convênio sobre Direitos Humanos e Biomedicina ou Convênio de Oviedo é o primeiro Tratado Internacional sobre bioética, promovido pelo Conselho da Europa e assinado em Oviedo em 04 de abril de 1997. O texto da Convenção estabelece expressamente que o interesse e o bem-estar do ser humano devem prevalecer sobre os interesses da sociedade ou da ciência, e introduz também o princípio do consentimento informado. Em relação a este princípio não pode levar ao cabo uma intervenção no âmbito da saúde até que a pessoa interessada tenha dado consentimento expresso, que necessariamente deve ser livre e informado, concretamente se refere a "informação adequada sobre o propósito e a natureza da intervenção e sobre suas consequências e riscos." ${ }^{23}$ Assim, a pessoa interessada pode a todo momento revogar livremente seu consentimento.

A jurisprudência constitucional italiana definiu o consentimento informado como "uma síntese de todos os direitos fundamentais da pessoa: o direito à autodeterminação e o direito à saúde, considerando que toda pessoa tem direito a ser tratada medicamente, também tem direito a receber informação adequada sobre a natureza e à possibilidade de evolução da via terapêutica à qual pode ser submetida, assim como aos tratamentos alternativos, informação que deve ser a mais completa possível, precisamente para garantir a escolha livre e informada por parte do paciente e, por sua própria liberdade pessoal, de acordo com o artigo 32.2 da Constituição (Italiana). ${ }^{24}$

A Carta dos Direitos Fundamentais da União Europeia também estabelece que "o consentimento da pessoa interessada deve ser pessoal, livre e informado", ${ }^{25}$ revogável e específico (também em relação com as possíveis fases alternativas e consequentes dos riscos da operação cirúrgica). ${ }^{26}$ Neste ponto, entretanto, a jurisprudência italiana já interveio muito antes da entrada em vigor da Carta de Niza. ${ }^{27}$

Sobre o tema, objeto do estudo, também interveio, o TEDH que inicialmente estabeleceu em sua jurisprudência que o direito à vida não pode derivar do direito diametralmente oposto da

\footnotetext{
${ }_{22}$ Sobre a tutela multinível de direitos permita-se resgatar P. BILANCIA, F. G. PIZZETTI, Aspetti e problemi del costituzionalismo multilivello, Milano, Giuffrè, 2004.

${ }^{23} \mathrm{O}$ artigo $5^{\circ}$ prescreve que: "Não poderá levar a cabo uma intervenção no campo da saúde a menos que a pessoa interessada tenha dado seu consentimento livre e informado. A pessoa receberá em primeiro lugar informação adequada sobre a finalidade e a natureza da intervenção, assim como sobre suas consequências e riscos. A pessoa interessada poderá a qualquer momento revogar livremente seu consentimento."

${ }^{24}$ Cfr. Corte Const., n. 438/2008. Sobre a sentença em questão, consultar: R. BALDUZZI, D. PARIS, Corte costituzionale e consenso informato tra diritti fondamentali e ripartizione delle competenze legislative, en Rivista AIC, 23 aprile 2009 ; C. CASONATO, Il principio della volontarietà dei trattamenti sanitari fra livello statale e livello regionale, en Le Regioni, nn. 3-4, 2009.

${ }^{25} \mathrm{O}$ artigo $3^{\circ}$ assinala que: "Toda pessoa tem o direito à integridade física e moral No âmbito da medicina e da biologia, deve-se respeitar em particular, o consentimento livre e informado da pessoa interessada, em conformidade com os procedimentos estabelecidos pela lei, a proibição das práticas eugênicas, em particular as destinadas à seleção de pessoas, à proibição de fazer do corpo humano e suas partes fonte de benefícios, e à proibição da clonagem com fins de reprodução de seres humanos."

${ }^{26}$ Sobre o artigo em questão, ver: R. BIFULCO, Art. 3, en R. Bifulco, M. Cartabia, A. Celotto (coord), L'Europa dei diritti. Commento alla Carta dei Diritti Fondamentali dell'Unione Europea, Bologna, Il Mulino, 2001.

${ }^{27}$ Cfr. Casación. Civ., Sez. III, n. 364/1997.
} 
morte, salvo quando houver em discussão uma distorção inaceitável do disposto no artigo $2^{\circ}$ da Convenção. ${ }^{28}$ Assim mesmo, o TEDH considerou que o direito não podia se derivar dos artigos $3^{\circ}$, $8^{\circ}, 9^{\circ}$ e 14 da Convenção. O Tribunal também esclareceu que, inclusive quando o suicídio assistido é legal, o Estado não está obrigado, em virtude do artigo $8^{\circ}$ do Convênio, a dispor um suicídio seguro, digno e indolor mediante a obtenção de substâncias necessárias sem a correspondente prescrição médica, já que a receita médica garante que as decisões da pessoa não sejam precipitadas e que a prática não dê lugar a abusos. ${ }^{29}$

Em relação à interrupção da alimentação e hidratação artificiais, o TEDH estipulou que é necessário dar uma ampla margem de apreciação a favor dos Estados e que, por isso, a legislação do Estado membro, que permite a dita interrupção não infringe o artigo $2^{\circ}$ do Convênio, sempre e quando regule adequadamente os controles e as medidas de procedimentos necessários. ${ }^{30}$

Por último, cabe assinalar que o Convênio de Oviedo foi aprovado pelo Parlamento italiano com a Lei de autorização de ratificação n 145, de 28 de março de 2001 e foi ratificada pelo Presidente da República, apesar de que a ratificação nunca se depositou no Conselho Europeu. Isto também ensejou a apresentação de perguntas parlamentares nas quais se denuncia que, a iniciativa de não haver depositado o instrumento de ratificação constitui um grave obstáculo par a aplicação no ordenamento interno dos princípios estabelecidos na Convenção e debilita a posição da Itália, que há muito tempo está comprometida à nível internacional com a promoção dos direitos humanos, que pode estar afetada pela aplicação das novas tecnologias em ausência de prescrições médicas normativas adequadas. ${ }^{31}$

\section{Suicídio assistido e eutanásia}

O suicídio se define como o ato mediante o qual um indivíduo obtém a morte voluntária e conscientemente. ${ }^{32}$ Se parte da ideia de que este ato parece contrastar, em primeiro lugar, com o direito à vida do sujeito que a detém, compreende-se que a doutrina tem questionado durante muito tempo acerca da relação entre o suicídio, a autodeterminação e a vida humana, e por isso, sobre o equilíbrio entre o direito à autodeterminação individual e o direito à vida.

Para da doutrina embasa-se no artigo $5^{\circ}$ da Constituição (Italiana), que proíbe os atos de disposição sobre o próprio corpo quando causem uma diminuição permanente da integridade física

\footnotetext{
${ }^{28}$ Cfr. Pretty v. The United Kingdom, Sentença n . 2346/02, 29.04.2002. Sobre o assunto examinado ver A. SZERLETICS, Paternalism and euthanasia: the case of Diane Pretty before the European Court of Human Rights, en Diritto \& questioni pubbliche, $\mathrm{n}$. 10, 2010. Sobre a orientação do TEDH sobre o tema do suicídio assistido ver R. BIFULCO, Esiste un diritto al suicidio assistito nella CEDU?, en Quaderni costituzionali, n. 1, 2003

29 Cfr. Haas v. Switzerland, App. n ${ }^{\circ}$ 31322/07, 20.01.2011.

${ }^{30}$ Cfr. Lambert and Others v. France, Gran Sala, App. n. 46043/14, 5.06.2015. A respeito ver: C. CASONATO, Un diritto difficile. il caso "Lambert" fra necessità e rischi, en La nuova giurisprudenza civile commentata, n. 9, 2015.

${ }^{31}$ Cfr., por último, a questão Auto n. 1-00848 Senado, de 12 de outubro de 2017.

32 Ver: S. CURRERI, Lezioni sui diritti fondamentali, cit., 236.
} 
(ou quando sejam contrários à lei, à ordem pública ou à moral), ou seja, a proibição de dispor da própria vida. Em outras palavras, se o indivíduo não pode dispor validamente da sua integridade física, a fortiori não poderá dispor validamente da sua própria vida. ${ }^{33}$ Outras alternativas consideraram o contrário, que uma leitura da norma originalmente "organicista" do artigo $5^{\circ}$ da Constituição (Italiana), através do prisma dos princípios fundamentais reconhecidos pela Constituição republicana, inevitavelmente teria que ampliar a esfera de domínio do indivíduo sobre seu próprio corpo e, consequentemente, incluído sobre sua própria vida. ${ }^{34}$

Segundo o sistema penal, que remonta à era Republicana, o suicídio, assim como os atos de disposição do corpo que acarretam lesões permanentes, vinham sendo julgados desfavoravelmente pelo legislador, que tratava de reprimir o fenômeno através da legislação penal. ${ }^{35} \mathrm{O}$ ordenamento prevê para tanto expressamente no artigo 580 do Código Penal o crime de instigação ou assistência ao suicídio, assim como no artigo 579 do Código Penal, o crime de homicídio consentido.

Porém, é importante destacar, desde já, a sanção não se estende ao suicida em si mesmo: é possível tentar impedi-lo, mas se alguém tenta tirar a vida sem êxito, não incorrerá em qualquer responsabilidade penal. ${ }^{36}$ As tentativas jurisprudenciais de levar a cabo uma leitura restritiva das normas em questão (para as quais a ajuda ao suicídio penalmente relevante seria somente a que implica um reforço da vontade suicida), ${ }^{37}$ rompeu com a postura da Corte de Cassação, que em vez disso considerou também como penalmente relevante a mera ajuda material. ${ }^{38}$

A desvantagem legal é tal que a sanção não afeta somente o ato suicida, senão também a outras condutas que podem facilitar ou difundir de alguma maneira esta prática: por assim dizer, as publicações e transmissões radiotelevisivas com conteúdos impressionantes, tais como a difusão do fenômeno ou a publicação em meios de imprensa de retratos de suicídios, estão proibidos. ${ }^{39}$

De acordo com a reconstrução clássica, resulta que, da inalienabilidade do direito à vida, ao qual se refere o artigo $2^{\circ}$ da Constituição (Italiana) e da proibição de tratamento médico obrigatório não imposto pela lei em conformidade com o artigo 32 da Constituição, se extrai a consequência de que não existe em nosso ordenamento constitucional (italiano) um "direito ao suicídio" do indivíduo. ${ }^{40}$ Este enfoque, ademais, parece estar corroborado pela jurisprudência do TEDH a que

\footnotetext{
$\overline{33}$ Sobre esta questão pode consultar, L. EUSEBI, Sul mancato consenso al trattamento terapeutico: profili giuridico-penali, en Rivista italiana di medicina legale, 1995, 734; M. DOGLIOTTI, Persone fisiche: capacità, status, diritti, Torino, Giappichelli, $2014,46$.

${ }_{34}$ Sobre a disponibilidade do corpo, ver: R. ROMBOLI, I limiti della libertà di disporre del proprio corpo nel suo aspetto "attivo" e in quello "passivo", en Il Foro italiano, 1991.

35 Ver: V. MANZINI, Trattato di diritto penale italiano, VIII, Torino, UTET, 1985, 111 ss.; P. NUVOLONE, Linee fondamentali di una problematica del suicidio, en AA. VV. Suicidio e tentato suicidio in Italia, Rapporto della Commissione di studio del Centro nazionale di prevenzione e difesa sociale (CNPDS), Milano, Giuffrè, 1967, 391.

${ }^{36}$ Sobre a ineficiência afastada da sanção penal com referência ao suicídio, ver C. BECCARIA, Dei delitti e delle pene, ed. (coord) P. Calamandrei, Firenze, Le Monnier, 1965.

${ }^{37}$ Cfr. Tribunal penal de Messina, sentença de 10 de junho de 1997.

${ }^{38}$ Cfr. Casación Penal)., (Secc). I, sentença n. 3174 de 12 março de 1998.

${ }^{39}$ No mesmo sentido, S. CURRERI, Lezioni sui diritti fondamentali, cit., 237, que aporta por exemplo o art. 14 de la ley $\mathrm{n}^{\circ}$ 47/1948 ou o art. 30 da lei no 223/1990, ou ainda o art. 114 do TULPS.

${ }^{40}$ Neste sentido ver, S. CURRERI, Lezioni sui diritti fondamentali, cit., 237.
} 
se refere o parágrafo anterior. Segundo este enfoque, portanto, o suicídio não é nem sequer uma liberdade, e não é um comportamento proibido, mas sim uma "conduta legalmente tolerada", com referência, portanto, somente ao sujeito que tenta se suicidar, e não a respeito a outros sujeitos que contribuíram a sua determinação. ${ }^{41}$

Outros enfoques doutrinários mais recentes enfatizaram como uma leitura do direito à saúde em referência ao artigo 32 da Constituição (Italiana), através dos princípios dos direitos de personalidade, pluralistas e da dignidade humana reconhecidos pelo artigo $2^{\circ}$ da Constituição, deveria conduzir inevitavelmente a reconhecer a margem mais ampla possível sobre a disponibilidade da pessoa sobre seu próprio corpo e sua vida. ${ }^{42}$ Segundo esta perspectiva, o suicídio já não deve ser considerado como um ato ilegal não permitido pelo ordenamento ou como um ato tolerado, senão como um ato "neutro" em termos de legalidade. ${ }^{43}$

A eutanásia se diferencia do suicídio em razão de que envolve uma ação (ou omissão) dirigida especificamente a terminar com a vida de outros. Além desta caracterização, o conceito de eutanásia determinou e determina uma série de comportamentos muito diferentes, que vão desde práticas eugênicas reais até atividades estritamente terapêuticas. ${ }^{44}$ Entretanto, é verdade que o termo que vem sendo assumido gradualmente, e especialmente nos últimos anos, é a prática dirigida a pôr fim à vida do sujeito que considera intolerável a continuação da existência (devido ao sofrimento insuportável causado pela enfermidade e/ou a impossibilidade de se autoprover).

Na eutanásia médica pode por sua vez distinguir-se entre eutanásia passiva ou eutanásia ativa. A eutanásia passiva é, antes de tudo, a conduta dirigida a aliviar os sofrimentos do paciente, cuja vida está finalizando já de forma natural, também através da administração de substâncias (por exemplo, morfina) que possa encurtar sua existência, sem que seja a causa da morte já em andamento: um exemplo de tais práticas pode ser chamada "sedação profunda". ${ }^{45}$ A noção de eutanásia passiva também inclui a suspenção de tratamentos que mantêm artificialmente vivo um indivíduo que, sem a administração de tais tratamentos, morreria naturalmente: um exemplo de tais práticas pode ser

\footnotetext{
41 Ibidem.

${ }^{42}$ Sobre este assunto pode consultar C. CASONATO, Introduzione al biodiritto, Torino, Giappichelli, 2009; A. SANTOSUOSSO, Corpo e libertà. Una storia tra diritto e scienza, Milano, Raffaello Cortina, 2001; P. VERONESI, Il corpo e la Costituzione. Concretezza dei"casi" e astrattezza della norma, Milano, Giuffrè, 2007; R. ROMBOLI, I limiti della libertà di disporre del proprio corpo nel suo aspetto "attivo" e in quello "passivo", cit.

43 A respeito ver S. CANESTRARI, Biodiritto (diritto penale), cit.; P. VERONESI, Uno statuto costituzionale del corpo, cit., 150 ss.; M. NISTICÒ, Il suicidio come "indifferente giuridico" fra diritto alla vita e tutela della libertà di autodeterminazione, en Il Foro italiano, n. 9, 2009.

44 Sobre a possível definição do conceito de eutanásia ver M. PORZIO, Eutanasia, en Enciclopedia del diritto, XVI, Milano, Giuffrè, 1967.

${ }^{45}$ Ver M. MANFREDINI, Eutanasia, in Dizionario di criminologia, vol. I, Milán, Vallardi, 1943, 338, observa que o conceito de eutanásia "em si mesmo contém a indicação do feito objetivo da boa morte e em um primeiro momento somente se define como uma ação de legalidade indubitável levada a cabo pelos médicos para aliviar a dor da agonia. Isto não era a causa da morte, que já estava em curso, senão que se deu uma forma indolor". Sobre os perfis legais subjacentes à prática da "sedação profunda" ver F. G. PIZZETTI, "Ai confini delle cure": la sedazione palliativa (o terminale) tra diritto di non soffrire e diritto di morire, en P. Macchia (coord), Ai confini delle cure. Terapia, alimentazione, testamento biologico. Profili clinici, giuridici, etici, Napoli, ESI, 2012.
} 
considerada a interrupção já mencionada da alimentação, a hidratação ou a respiração artificiais. ${ }^{46}$ De outra maneira, por eutanásia ativa nos referimos, a partir de um caso de suicídio materialmente assistido, onde basicamente é o comportamento do interveniente é que causa diretamente a morte do paciente, por exemplo, no caso de suspensão ou interrupção dos tratamentos administrados. ${ }^{47}$

A partir desta perspectiva, foi observada de maneira consensual que no debate social, político e jurídico sobre a eutanásia, o progresso da ciência médica tem realizado um papel absolutamente insignificante. Se de um lado permitiu estender artificialmente a vida humana, por outro considerou que em alguns casos, a qualidade da mesma não seja adequada. ${ }^{48}$ Neste sentido, é possível extrair que o próprio progresso da ciência médica coloca em conflito, em alguns casos, o princípio da dignidade humana. Por isso é extremamente importante, e muito difícil, identificar os casos do chamado "ensinamento terapêutico", e em consequência aqueles casos nos quais os tratamentos implementados sejam invasivos, onerosos, dolorosos em comparação com as possibilidades concretas de cura ou melhora, até então inexistentes. ${ }^{49} \mathrm{O}$ ensinamento terapêutico está proibido pelo código deontológico médico, ${ }^{50}$ e em relação a estes casos, também foram registradas algumas aberturas por parte da Igreja Católica. ${ }^{51}$

Independentemente da proibição da eutanásia não voluntária (na qual não tenha sido o paciente quem tenha solicitado, ou manifestado previamente sua vontade neste sentido) que integraria por exemplo o artigo 575 do Código Penal (Italiano), o crime de homicídio puro e simples, tampouco pode ser considerado lícito na atualidade da eutanásia ativa, em razão de que o comportamento do médico que causa a morte do paciente ao pedido expresso deste último, integraria o crime de homicídio consentido em conformidade com o artigo 579 do Código Penal. ${ }^{52}$

A eutanásia ativa ou o suicídio assistido, é por exemplo, legal em alguns ordenamentos ocidentais (ainda que realmente sejam poucos), entre os que se encontram, por exemplo, os Países Baixos, Bélgica, Luxemburgo, Suíça e em alguns Estados dos Estados Unidos da América, enquanto

\footnotetext{
$\overline{{ }^{6}}$ A respeito ver A. D'ALOIA, Eutanasia (diritto costituzionale), en R. Bifulco, A. Celotto, M. Olivetti (coord), Digesto delle discipline pubblicistiche, Torino, Utet, 2012. Sobre a problemática relativa à inserção de tais práticas "passivas" no âmbito do conceito de eutanásia ver S. CANESTRARI, Principi di biodiritto penale, Bologna, Il Mulino, 2016, 63 ss.

47 Ver D'ALOIA, Eutanasia (diritto costituzionale), cit. Véase también lo recogido en A. PERÉZ MIRAS, G. M. TERUEL LOZANO, E. C. RAFFIOTTA (coords), Sfide per i diritti della persona nel XXI secolo: Vita e Scienza, Cizur Menor, Thomson Reuters - Aranzadi, 2013.

${ }^{48}$ Neste sentido S. CURRERI, Lezioni sui diritti fondamentali, cit., 237.

49 A respeito pode consultar D. LAMB, Etica alle frontiere della vita. Eutanasia e accanimento terapeutico, Bologna, Il Mulino, 1998.

${ }^{50}$ Cfr. Artículo 16: "O médico [...] não realiza nem insiste em procedimentos diagnósticos e intervenções terapêuticas clinicamente inapropriados e eticamente desproporcionais, dos que não ficam esperando de maneira fundamentada um benefício real para a saúde e/ou uma maneira na qualidade de vida."

${ }^{51}$ Cfr. canon 2278 catecismo da Igreja Católica, prescreve que "A interrupção de procedimentos médicos onerosos, perigosos, extraordinários ou desproporcionais com respeito aos resultados esperados pode ser legítima. Neste caso temos a renúncia à 'obstinação terapêutica'. Não queremos procurar a morte: aceitamos que não podemos evitá-la. As decisões devem ser tomadas pelo paciente, se tem competência e capacidade, ou, de outro modo, por aqueles que legalmente têm o direito, sempre respeitando a vontade razoável e os interesses legítimos do paciente."

${ }^{52}$ Ver também o art. 36 do código deontológico médico que estabelece que, "o médico, através de uma petição do paciente, não deve realizar nem promover tratamentos dirigidos a causar a morte."
} 
que estão sendo produzidas outras aberturas jurisprudenciais, como no Canadá e na Colômbia. ${ }^{53}$ Particularmente, em relação à Suíça teve certa relevância, incluídas nas notícias, onde existem estruturas especiais que ofertam um serviço real com referência ao final da vida, um serviço que vai desde a preparação de material informativo até a assistência legal nas fases terminais da vida e incluindo qualquer dúvida que posso surgir depois da morte..$^{54}$

Com referência à eutanásia ativa, argumentou-se que sempre está proibida em virtude da prevalência do princípio da dignidade humana sobre a autodeterminação individual. ${ }^{55} \mathrm{~A}$ postura contrária entende que a imposição de um "quase dever" de viver em nome da dignidade humana está embasada em enfoques paternalistas que excedem uma leitura moderna do emaranhado de princípios constitucionais fundamentais. ${ }^{56}$

Com referência à eutanásia passiva, deve ser considerado que, à luz das evoluções doutrinárias e jurisprudenciais acima mencionadas, cabe deduzir legitimamente a negativa ao tratamento de saúde por parte do interessado. De antemão, na doutrina e na jurisprudência, argumentou-se que a recusa ao tratamento não implica o reconhecimento de um "direito a morrer", senão de um direito a deixar-se morrer, ao não impedir o curso natural de uma enfermidade através de um comportamento que, por isso é passivo ou omissivo. ${ }^{57}$ Agora parece necessário incluir a hidratação e a nutrição artificiais no marco dos tratamentos de saúde previstos pelo artigo 32 da Constituição (Italiana) que o paciente pode recusar livremente, e não no contexto de "atos eticamente devidos" ${ }^{58}$ Finalmente, a eutanásia passiva deveria ser considerada legítima nos casos de "ensinamentos terapêuticos" e, portanto, naqueles casos onde as terapias implementadas são inúteis. ${ }^{59}$

Entretanto, a Corte Constitucional declarou a respeito, que

o indivíduo pode recusar um tratamento médico e sua vontade consciente deve ser respeitada inclusive quando a negativa se refere a tratamentos que salvem vidas e tudo isso se aplica não somente em relação entre o Estado e os cidadãos, mas

\footnotetext{
${ }_{53}$ Para um reconhecimento da legislação existente nas diferentes jurisdições ver C. FOCARELLI, Euthanasia, en Max Planck Encyclopedia of Public International Law, 2013.

${ }^{54}$ Sobre a normativa suíça na matéria ver E. CRIVELLI, Gross c. Svizzera: la Corte di Strasburgo chiede alla Svizzera nuove e più precise norme in tema di suicidio assistito, en Rivista AIC, n. 3, 2013; A. BARAGGIA, L'assistenza organizzata al suicidio in Svizzera: verso una regolamentazione?, en Quaderni costituzionali, n. 2, 2010.

${ }_{55}$ Consultar: G. RAZZANO, Dignità nel morire, eutanasia e cure palliative nella prospettiva costituzionale, Torino, Giappichelli, 2014.

56 Ver: G. GEMMA, Dignità ed eutanasia: non c'è antitesi. Note a margine di un'opera recente di una costituzionalista cattolica, en Materiali per una storia della cultura giuridica, n. 1, 2016.

${ }^{57}$ Cfr. V. Casación Civil, n. 21748/2007. Ver: S. CURRERI, Lezioni sui dirittifondamentali, cit., 240. Sobre este mesmo assunto pode ser consultado A. D'ALOIA, Ildiritto di rifiutare le cure e la fine della vita. Un punto di vista costituzionalesul caso Englaro, en Dirittiumani e dirittointernazionale, n. 2, 2009. Para uma perspectiva comparada, J. LUTHER, The judge's power over life and death, cit., 11 ss.

${ }^{58} \mathrm{Al}$ respeito ver C. CASONATO, F. CEMBRANI, Il rapporto terapeutico nell'orizzonte del diritto, en S. Rodotà, P. Zatti, Trattato di biodiritto, Milano, Giuffrè, 2011, 64 ss. Sobreo debate desta questão ver também: G. BATTIMELLI, Nutrizione ed idratazione artificiale (NIA) nei documenti di alcune società scientifiche: una riflessione bioetica, enMedicina e morale, n. 3, 2011; A, SCALERA, Alimentazione e idratazione artificiale, en Studium iuris, n. 4, 2009; E. COLOMBETTI, Alimentazione e idratazione artificiale come problema di giustizia, en Medicina e morale, n. 6, 2009.

59 Sobre esta questão, G. RAZZANO, Accanimento terapeutico o eutanasia per abbandono del paziente? Il caso Lambert e la Corte di Strasburgo, en Rivista di BioDiritto, n. 3, 2015.
} 
também entre particulares, ou melhor dizendo, entre o paciente e seu médico, que deve respeitar a vontade do paciente como regra geral..$^{60}$

Por isso, em nosso ordenamento (italiano) não existe uma "obrigação à saúde" ou uma "obrigação à vida", ${ }^{61}$ exceto nos casos expressamente previstos pela Constituição e, por isso, substancialmente no caso de perigo para a saúde coletiva ${ }^{62}$ ou em cumprimento do dever de defesa da nação. ${ }^{63}$

No caso de Piergiorgio Welby, a autoridade judicial teve que afrontar o caso da eutanásia passiva já que, ainda que o paciente tenha expressado claramente sua vontade de pôr fim a sua existência, requeria-se uma ação positiva por parte de um terceiro para interromper os tratamentos que o mantinham artificialmente vivo, não podendo ele mesmo interrompê-los artificialmente e, em particular, desconectar-se do respirador que o mantinha artificialmente vivo. ${ }^{64} \mathrm{O}$ problema era, antes de tudo, a possível responsabilidade penal do profissional de saúde que se ocuparia do desligamento: enquanto que se o desligamento tivesse sido automático não haveria conduta ilícita. A partir daí foi necessário compreender como a conduta dos que se substituíam fisicamente (nos cuidados) ao paciente estava configurada legalmente, segundo a sua vontade mas colaborando efetivamente para a sua morte.

A autoridade judicial resolveu a complexa questão considerando que, o médico que procede o desligamento do respirador está cumprindo com um dever e, por isso, deve estar isento de responsabilidade penal em virtude da exceção a que se refere o artigo 51 do Código Penal (Italiano). Depois de uma primeira acusação formal formulada pelo G.I.P (juiz de Audiência Preliminar) que não aceitou a solicitação de demissão formulada pelo Ministério Fiscal, declarando que não havia fundamento para proceder em relação à posição do profissional de saúde pelo caso em questão. ${ }^{65}$

A jurisprudência se viu obrigada a fazer um esforço reconstrutivo adicional no caso Eluana Englaro, para decidir o particular percurso no qual a vontade do paciente de recusa dos tratamentos que o mantinham artificialmente vivo não é atual, senão que se expressou nesse sentido antes de que tenha ocorrido a enfermidade incapacitante (neste caso concreto, a menina esteve em estado

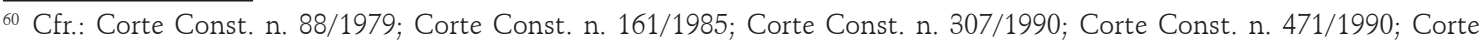
Const. n. 118/1996; Corte Const. n. 238/1996; Corte Const. n. 257/1996.

${ }^{61}$ Sobre este assunto pode consultar C. TRIPODINA, Articolo 32, cit.; A. ALGOSTINO, I possibili confini del dovere alla salute, en Giurisprudenza costituzionale, n. 5, 1996; M. COSULICH, La salute fra diritto dell'individuo e interesse della collettività: la questione della responsabilità individuale nella sanità, 2006, disponibile su www.provinz.bz.it.

62 Ver S. CURRERI, Lezioni sui diritti fondamentali, cit., 234 ss.

${ }^{63}$ Este caso, tampouco parece ser completamente combatido com uma interpretação evolutiva dos princípios constitucionais até agora mencionados, da mutilação da própria pessoa para escapar do serviço militar (Libro II, Título II, Capítulo IV y Artículo 242 do código penal militar de paz e artigos 112 e 115 do código penal de guerra militar). A respeito, P. CURATOLA, Automutilazione (dir. pen.), en Enciclopedia del diritto, IV, Milano, Giuffrè, 1959.

${ }^{64}$ Cfr. Trib. Roma, decisión del 15.12.2006.

${ }^{65}$ A respeito ver, A. PIZZORUSSO, Il caso Welby: il divieto di non liquet, cit.; P. VERONESI, Sul diritto a rifiutare le cure salvavita prima e dopo il caso "Welby" - una replica, cit.; F. VIGANÒ, Esiste un diritto a "essere lasciati morire in pace"? Considerazioni a margine del caso Welby, in Rivista italiana di diritto processuale penale, 2007; V. POCAR, Il caso di Piergiorgio Welby e il diritto di autodeterminazione del malato, en I diritti dell'uomo, n. 2, 2007. 
vegetativo irreversível durante mais de quinze anos) e, por isso, é representada pelo tutor (neste caso, o pai da menina) ${ }^{66}$ A Corte de Cassação considerou que o tratamento de hidratação e alimentação artificiais podiam interromper a situação, sempre que "a condição do estado vegetativo seja embasada em uma apreciação clínica rigorosa, irreversível e que não haja base médica segundo os estandartes científicos reconhecidos internacionalmente, que permitam supor a menor possibilidade de recuperação da consciência, ainda que seja débil e a percepção do mundo exterior", e que a solicitação formulada pelo tutor

seja realmente expressiva, com base em elementos probatórios claros, unívocos e convincentes da própria voz do paciente, a partir de suas declarações anteriores ou sua personalidade, de seu estilo de vida e de suas convicções, correspondente a sua forma de conceber a ideia de dignidade pessoal, antes de cair em um estado de inconsciência. ${ }^{67}$

A falha em questão também deu lugar a um acalorado choque institucional (até o ponto de que inclusive se falou de uma verdadeira "competência" entre os poderes do Estado), ${ }^{68}$ com o Presidente da República que se negou a assinar o Decreto-Lei no qual o Governo pretendia proibir a suspensão da hidratação e a alimentação artificiais do paciente em estado vegetativo, ${ }^{69}$ a Câmara dos Deputados e Senadores que formularam um conflito de atribuição de competências ao Tribunal de Cassação, considerando sua esfera de atribuição vulnerável com a função legislativa (apelação logo declarada inadmissível pela Corte Constitucional através da Ordenanza n $\left.{ }^{\circ} 334 / 2008\right),{ }^{70}$ e a menina finalmente faleceu enquanto o Senado discutia um projeto de lei que basicamente seguia o conteúdo do decreto que o Presidente da República havia negado a assinar.

A sentença em questão tampouco foi isenta de crítica doutrinária, concretamente foi criticada, em parte pelo suposto princípio da indisponibilidade da vida humana e, por outra parte, pelo princípio da precaução, segundo o qual a única vontade válida do paciente sobre o final da vida é a atual, não podendo outorgar relevância (à vontade) anteriormente manifestada

\footnotetext{
${ }^{66}$ Ver, S. CANESTRARI, F. MANTOVANI, A. SANTOSUOSSO, Riflessioni sulla vicenda di Eluana Englaro, en Criminalia, 2009; F. G. PIZZETTI, Sugli ultimi sviluppi del caso Englaro: limiti della legge e progetto di vita, em Politica del diritto, n. 3, 2009; T. GROPPI, Il caso Englaro: un viaggio alle origini dello Stato di diritto e ritorno, en Politica del diritto, n. 3, 2009; M. LUCIANI, L'emanazione presidenziale dei decreti-legge (spunti a partire dal caso E.), en Politica del diritto, n. 3, 2009.

${ }^{67}$ Cfr. Casación Civil, (Secc) I, sentencia n. 21748 del 16 octubre 2007.

68 V. TONDI DELLA MURA, I rischi della competizione regolativa e valoriale fra i diversi poteri dello Stato (riflessioni a margine del "caso Englaro"), enTeoria del diritto e dello Stato, nn. 2-3. 2009, 380. Sobre el tema véase también V. CERULLI IRELLI, In margine al caso E.: sui limiti della funzione legislativa, en Politica del diritto, n. 3, 2009; T. GROPPI, Il caso Englaro: un viaggio alle origini dello Stato di diritto e ritorno, en Politica del diritto, n. 3, 2009.

69 Sobre a questão ver: M. LUCIANI, L'emanazione presidenziale dei decreti-legge (spunti a partire dal caso E.), en Politica del diritto, n. 3, 2009; F. G. PIZZETTI, Sugli ultimi sviluppi del caso Englaro: limiti della legge e progetto di vita, en Politica del diritto, n. 3, 2009.

70 Sobre esta questão ver, R. ROMBOLI, Il conflitto tra poteri dello Stato sulla vicenda Englaro: un caso di evidente inammissibilità, en Il Foro.it, 2009; R. BIN, Se non sale in cielo, non sarà forse un raglio d'asino? (a proposito dell'ord. 334/2008), en Forum di Quaderni costituzionali, 2008.
} 
em situações radicalmente diferentes. ${ }^{71}$ Ainda mais problemático, segundo a reconstrução que ora se está examinando, é o caso no qual a vontade anterior nem sequer é atribuída de maneira unívoca ao paciente, senão que é manifestada por um terceiro (como no caso de Englaro). Em outras palavras, as decisões deste tipo somente podem ser tomadas por aqueles que realmente estão vivendo as complexas situações mencionadas, já que precisamente tais experiências podem mudar profundamente o enfoque individual de questões como o fim da vida e a dignidade humana. ${ }^{72}$

Notadamente, as conclusões finais da Corte Constitucional (Italiana) parecem ser consequência da necessidade de resposta à carência de um grave e persistente vazio jurídico, pela presença de uma prolongada inatividade por parte do legislador para responder às necessidades individuais de um caso concreto e, ademais, estas conclusões parecem estar respaldadas tanto pelas fontes do Direito Internacional Convencional (o Convênio de Oviedo citado anteriormente) ${ }^{73}$ como pelo Código deontológico médico. ${ }^{74}$

Assim, pois, diante do constante silêncio do legislador pelo caso Englaro, foi a autoridade judicial que teve que assumir a responsabilidade de resolver novas e complexas questões relativas ao final da vida. A Corte de Cassação mostrou neste ponto algumas aberturas sobre a possibilidade sobre as quais o sujeito interessado disponha validamente para o futuro sobre os tratamentos de saúde e, por isso, declare a priori quais tratamentos pretende aceitar ou recusar nos casos de uma incapacidade futura (a jurisprudência inclusive considerou que para este fim era possível nomear um administrador de apoio)..$^{75}$

De forma diversa, outras experiências puseram ênfase (aparentemente contrárias à tendência), no requisito necessário à atualidade da vontade do enfermo. Neste sentido encontramos, por exemplo, o caso de testemunhas de Jeová que portava uma etiqueta (adesivo) onde contava a descrição "sem sangue", e ao que, entretanto, foram praticadas transfusões de sangue para salvarthe de um grave perigo para sua vida (enquanto estava inconsciente). Em geral, a jurisprudência sobre à recusa das hemotransfusões pelos testemunhas de Jeová, como prática proibida pela sua religião, confirmou a legalidade desta recusa inclusive quando se supõe um grave risco para a vida. ${ }^{76}$

\footnotetext{
$\overline{71}$ Para as leituras mais críticas do caso e a intervenção da autoridade judicial, ver M. L. DI BITONTO, Sulla decisione del giudice del caso Englaro e sulle sue implicazioni, en Ragiusan, 2009; P. BECCHI, L'imperialismo giudiziario. Note controcorrente sul caso Englaro, en Rivista internazionale di filosofia del diritto, n. 3, 2009.

72 Sobre o debate relativo à efetiva avaliação dos desejos do paciente e as complexas questões constitucionais que as incluem, podem ser consultadas as profundas reflexões em F. G. PIZZETTI, Alle frontiere della vita. Il testamento biologico tra valori costituzionali e promozione della persona, cit., passim.

${ }^{73} \mathrm{O}$ artigo $9^{\circ}$ do Convênio estabelece que "se levará em conta os desejos expressados anteriormente à intervenção médica por parte de um paciente que, no momento da intervenção não posso expressar sua vontade."

${ }^{74} \mathrm{O}$ artigo 34 do Código de ética médica, antes da regulação das declarações antecipadas de tratamento, estabelecia que: "O médico deve se manter, em razão de a sua dignidade, liberdade e independência profissional, à vontade de curar, livremente expressado pela pessoa. Se o paciente não puder expressar sua própria vontade, em caso de grave perigo para sua vida, não pode deixar de considerar o que foi manifestado anteriormente pelo paciente."

75 Cfr. Casación Civil Secciones Unidas, n. 27145/2008; Trib. Modena, 5.11.2008; Trib. Treviso 1.2011. Véase S. CURRERI, Lezioni sui diritti fondamentali, cit., 234 ss.

${ }^{76}$ Cfr. Tribunal Penal de Apelación de Cagliari, sentença de 13.12.1982. Ver a respeito: V. CRISAFULLI, In tema di emotrasfusioni obbligatorie, en Diritto e società, n. 3, 1982. Entretanto, os pais não podem se opor à negativa em nome e representação
} 
Entretanto, o Tribunal de Cassação considerou neste caso que a conduta do profissional de saúde que havia levado a cabo as transfusões sobre a pessoa inconsciente e que, por isso, era incapaz de reiterar sua negativa, era lícita precisamente porque a vontade se expressou em um estado de boa saúde e de forma preventiva, não pode ser considerado válido e atual em uma situação de emergência e grave risco para a vida. ${ }^{77}$

As hipóteses mencionadas das decisões sobre o final da vida se produziram antes da adoção da lei sobre o testamento vital em nosso ordenamento jurídico italiano (contrariamente ao que fizeram muitos outros sistemas jurídicos europeus, como Reino Unido, França, Alemanha, os Países Baixos e Espanha ${ }^{78}$ ) e, pelo contrário, instigaram por diversas maneiras a opinião pública e, com dificuldade, ao legislador a intervir no assunto pelos anos de vazio legislativo. Neste contexto, o Conselho Europeu adotou a resolução n 1.859 de 25 de janeiro de 2012, a qual se recomenda aos Estados membros (que ainda não tenham feito) de que aprovem, o mais rápido possível, uma lei sobre declarações antecipadas de tratamento de saúde conforme a disposição no Convênio de Oviedo.

Finalmente, o Parlamento italiano, aprovou, não sem demora, a Lei $n^{\circ} 219$, de 22 de dezembro de 2017, que contém "Normas em matéria de consentimento informado e disposições relativas ao tratamento prévio." A Lei tentou dar uma solução completa e orgânica de algumas (ou todas) às questões problemáticas relativas ao fim da vida, incorporando em muitos casos os melhores enfoques da jurisprudência anteriormente descrita. A Lei regula em particular: o consentimento informado; o direito do paciente a recusar o tratamento; a terapia da dor e a sedação profunda; o direito do paciente de recusar a nutrição e hidratação artificiais; os direitos e deveres do médico respectivos à vontade expressa do paciente sobre o tema do fim da vida; a declaração de tratamento antecipada (o direito dos pacientes capazes de entender e querer dispor validamente para o futuro em relação aos tratamentos de saúde que desejam receber nos casos de incapacidade de autodeterminação superveniente). ${ }^{79}$

Apesar da Lei n 219/2017 ter realizado um indubitável passo à frente do legislador até uma regulação progressiva sobre os problemas relativos ao final da vida, muitas situações problemáticas

da criança, já que neste último caso deve prevalecer o interesse superior da criança, em virtude do chamado "princípio puerocêntrico" disposto no sistema constitucional. Cfr., por todos, Casación Penal Sección I, sentença de 13.12.1983. No mesmo sentido Cfr. Tribunal de Primera Instancia de Roma de 3.4.1997. A respeito ver: G. PELLEGRINO, Il rifiuto delle trasfusioni da parte de i testimoni di Geova; tra diritto costituzionale all'autodeterminazione in materia sanitaria e attualità del dissenso, in Giurisprudenza italiana, n. 5, 2009; P. CENDON, Testimoni di Geova, trasfusioni di sangue e principio di autodeterminazione, in Minori giustizia, n. 4, 2008; G. FACCI, I testimoni di Geova ed il "dissenso" all'atto medico, en Responsabilità civile e previdenza, n. 1, 2007.

77 Cfr. Casación Civil Sección III n. 23676/2008.

${ }^{78}$ A respeito ver: D. VESHI, G. NEITZKE, Advance directives in some Western European Countries: a legal and ethical comparison between Spain, France, England, and Germany, en European Journal of Health Law, vol. 22, n. 4, 2015. Para uma perspectiva comparada, cfr. El informe La disciplina del testamento biologico in alcuni Paesi (Francia, Germania, Paesi Bassi, Regno Unito, Spagna, Stati Uniti), a cargo del Servicio de Estudios del Senado, março 2009.

79 Sobre a lei objeto e exame, pode consultar: C. TRIPODINA, Tentammo un giorno di trovare un "modus moriendi" che non fosse il suicidio né la sopravvivenza. Note a margine della legge italiana sul fine vita, in Quaderni costituzionali, n. 1, 2018; A. SANTOSUOSSO, Questioni false e questioni irrisolte dopo la legge n. 219/2017, en Rivista di BioDiritto, n. 1, 2018 ; C. CASONATO, Forum: la legge n. 219 del 2017, norme in materia di consenso informato e di disposizioni anticipate di trattamento. Introduzione: la legge 219 fra conferme e novità, en Rivista di BioDiritto, n. 1, 2018. 
seguem "descobertas" e ainda hoje estão fora do âmbito de aplicação da norma vigente, com a consequência natural de que novamente deve ser a autoridade judicial a que supra o vazio normativo, como geralmente ocorre com respeito às questões mais recentes ou controversas. ${ }^{80}$

Assim surgiu com dramática relevância no recente caso de Fabiano Antoniani (conhecido pelo nome artístico de "DJ Fabo"), ${ }^{81}$ um jovem que, em estado de tetraplegia, cegueira e falta de autonomia nas funções fisiológicas naturais, nas condições de irreversibilidade de seu status, pediu a seus entes queridos que procedessem a uma forma de suicídio assistido no estrangeiro (na Suíça) para pôr fim a uma vida que pela sua peculiaridade abriu o debate sobre a chamada eutanásia "ativa", destacando uma vez mais a necessária intervenção legislativa para regulamentar a maneira efetiva os interesses constitucionais implicados.

\section{0 caso Cappato - "DJ Fabo"}

Fabiano Antoniani ficou tetraplégico e cego depois de acidente de carro, permanecendo em um estado que qualificou de insuportável, ao que se somava a falta de autonomia na respiração e na alimentação, e os constantes e intensos espasmos e dores que sentia diariamente. $\bigcirc$ ativista e expoente político radical Marco Cappato, entrou em contato com a família Antoniani e lhes informou sobre as práticas de "suicídio assistido" na Suíça e, a pedido desta última, o transportou em carro até uma clínica na Suíça, onde se submeteu a um procedimento de eutanásia "ativa" (suicídio assistido medicamente), legal naquele ordenamento. Logo depois, Cappato se autodenunciou abertamente diante do Ministério Fiscal da República, com o propósito de iniciar um processo judicial através do qual esperava sensibilizar o legislador e a opinião pública sobre a contínua falta de regulação acerca dos temas relativos ao final da vida.

A Fiscalização, depois de abrir um expediente sobre o caso, pediu a demissão (apoiando-se para tanto na interpretação restritiva do artigo 580 do Código Penal, segundo o qual a ajuda ao suicídio relevante seria somente quanto se realiza na "fase executiva" da vontade suicida, e não também na fase meramente inicial), e subsidiariamente que se inserisse a questão da constitucionalidade do crime de ajuda ao suicídio. ${ }^{82} \mathrm{O}$ juiz da Indagação Preliminar, entretanto, recusou a solicitação e, em seu lugar, ordenou a imputação pelo crime de ajuda ao suicídio, conforme artigo 580 do Código Penal (Italiano) pela ação de que Cappato tenha reforçado a vontade suicida de Fabiano Antoniani, concretamente,

\footnotetext{
${ }_{80}$ Observa M. DOGLIANI, Introduzione, in M. Cavino, C. Tripodina (coord), La tutela dei diritti fondamentali tra diritto politico e diritto giurisprudenziale: "casi difficili" alla prova, Milano, Giuffrè, 2012, 2, que isto acontece com frequência naqueles casos que estão "nos limites do compromisso constituinte".

81 Pensado também nos recentes casos "estrangeiros" como o de Charlie Gard. Sobre este caso ver: D. SERVETTI, Dopo Charlie e gli altri "casi Gard", ripartiamo da alcune domande, en Corti supreme e salute, n. 1, 2018.

${ }^{2}$ Cfr. Fiscalía de la República de Milán, Petición de Archivo de 26 de abril de 2017, proc. 9609/2017 R.G.N.R., PP. MM. Siciliano e Arduini, indagato Cappato. Sobre la solicitud en cuestión véase P. BERNARDONI, Tra reato di aiuto al suicidio e diritto ad una morte dignitosa: la Procura di Milano richiede l'archiviazione per Marco Cappato, en Diritto penale contemporaneo, $\mathrm{n}$. 5, 2017.
} 
sugerindo a possibilidade de recorrer ao suicídio assistido na Suíça, colocando-o em contato com a clínica Dignitas (que lhe havia proporcionado o material informativo) e transportando-o fisicamente até a clínica. Em efeito, o artigo 580 do Código Penal pune, além dos que instigam outra pessoa ao cometimento do suicídio, todo aquele que facilite "de qualquer maneira" o suicídio. ${ }^{83}$

Ademais, cabe destacar que o comportamento daqueles que simplesmente se limitam a acompanhar alguém a uma clínica suíça para levar a termo um suicídio assistido tenha sido considerado penalmente irrelevante, com relação ao artigo 580 do Código Penal (Italiano), pelo Tribunal de Vicenza somente uns anos antes. ${ }^{84}$

De qualquer modo, o juízo que foi celebrado diante do Tribunal Penal de Milão, de onde uma vez celebrada a Fiscalização solicitou a absolvição do acusado. Entretanto, o Tribunal considerou que devia assumir a questão da constitucionalidade do crime a que se refere o artigo 580 do Código Penal, pois se é certo que Cappato não havia reforçado a intenção de se suicidar de Fabiano Antonioni (intenção que o mesmo já havia amadurecido de forma independente em um momento prévio ao contato com o acusado), o que exclui a ocorrência do crime de incitação ao suicídio, não há dúvida de que sim havia facilitado a conduta suicida, de modo que devia considerar-se que subsistia em termos abstratos, o delito de ajuda ao suicídio. ${ }^{85}$

Tribunal considerou que o crime de ajuda ao suicídio deveria ser entendido como suspeito de inconstitucionalidade:

a) na parte em que se incriminam a conduta de ajuda ao suicídio como uma alternativa à conduta de instigação e, por isso, independentemente de sua contribuição à determinação ou ao reforço da vontade do suicídio, considerando que esta norma contrasta com os artigos $2^{\circ}, 13$, parágrafos primeiro e 117 da Constituição Italiana (em relação com os artigos $2^{\circ}$ e $8^{\circ}$ do $\mathrm{CEDH}$, segundo a interpretação do Tribunal de Estrasburgo);

b) na parte na qual se estabelece que a conduta de facilitação da execução do suicídio que não afete o processo deliberativo do potencial suicida pode ser sancionada com um pena de prisão de 5 a 10 anos, sem distinção em relação à conduta de instigação, considerando que esta norma contrasta com os artigos $3^{\circ}, 13,25$ parágrafo segundo, e 27 parágrafo terceiro da Constituição (Italiana).

\footnotetext{
${ }^{83}$ Cfr. ordenanza del Juez de la Indagación Preliminar de Milano, 10 julio2017, juez Gargiulo, Imp. Cappato. Sobre la ordenanza objeto de examen puede consultarse P. BERNARDONI, Aiuto al suicidio: il G.I.P. di Milano rigetta la richiesta di archiviazione e dispone l'imputazione di Marco Cappato, en Dirittopenalecontemporaneo, nn. 7-8, 2017.

${ }^{84}$ Cfr. Tribunal de Vicenza, sentença de 2 março 2016.

${ }^{85}$ Cfr. Tribunal Penal de Milano, ord. 14 fevereiro 2018, Presidente Mannuccui Pacini, Juez Simi De Burgis, Imputado Cappato). Sobre la ordenanza objeto de examen M. FORCONI, La Corte d'Assise di Milano nel caso Cappato: sollevata questione di legittimità costituzionale dell'art. 580 c.p., en Diritto penale contemporaneo, n. 2, 2018.
} 
O Tribunal de Milão mencionou os casos Englaro e Welby e a jurisprudência do TEDH nos casos Haas v. Suiça de 2011 e Gross v. Suiça de 2014, como apoio para sustentar que, à luz da nova sensibilidade social e legal sobre o direito do indivíduo em decidir acerca de sua dignidade e o final de sua própria existência (também à luz da aprovação da Lei no 219/2017 anteriormente mencionada, e à luz dos princípios constitucionais que indubitavelmente inspiraram esta fonte), não se pode considerar que a simples facilitação do suicídio seja idôneo produzir um dano real aos direitos fundamentais do indivíduo.

Essencialmente, o Tribunal considerou que, as disposições combinadas do princípio dos direitos de personalidade (artigo $2^{\circ}$ da Constituição Italiana), do direito à liberdade pessoal (artigo 13 da Constituição), do direito à autodeterminação com respeito à assistência de saúde (artigo 32 da Constituição), à luz da jurisprudência do TEDH embasada nos artigos $2^{\circ}$ e $8^{\circ}$ do $\mathrm{CEDH}$ (como parâmetro interposto de conformidade com o artigo 117, inciso I, da Constituição) somente podem levar à conclusão de que no ordenamento constitucional (italiano) existe um verdadeiro direito a "decidir por quais meios e em que momento terminará a própria vida".

O Tribunal também considerou inaceitável, por exemplo o artigo $3^{\circ}$ da Constituição (Italiana), que as condutas de incitação ao suicídio e a mera ajuda ao suicídio sejam punidas com a mesma pena. ${ }^{86}$

A questão foi tratada pela Corte Constitucional (Italiana) através da sentença n 217/2018, na qual se considerou que:

a) do artigo $2^{\circ}$ da Constituição (e, no mesmo sentido, do artigo $2^{\circ}$ do CEDH), o Estado tem o dever de proteger a vida de todas as pessoas, mas tais disposições não é possível extrair, entretanto, o direito oposto a obter do Estado ou de terceiros uma verdadeira "ajuda para morrer". A postura da Corte Constitucional parece estar casada neste ponto com a reconstrução do TEDH no mencionado caso Pretty, no sentido de que não existem um "direito para morrer" ${ }^{87}$ no nosso ordenamento italiano (ou no convencional).

b) a norma penal a qual se refere o artigo 580 do Código Penal (Italiano) tem por objeto a proteção de interesses dignos de tutela no ordenamento constitucional e, mais concretamente, a proteção da vida da pessoa humana, que, segundo à Corte Constitucional, deve ser considerado um "valor em si mesmo". Isto também se aplica

\footnotetext{
${ }_{86}$ Para uma ampla reconstrução dos conteúdos da ordenanza e as questões jurídicas a partir delas implicadas, ver: R. ROMBOLI, In tema di istigazione al suicidio, en Il Foro italiano, n. 6, 2018; A. MASSARO, Il "caso Cappato" di fronte al giudice delle leggi: illegittimità costituzionale dell'aiuto al suicidio?, en Diritto penale contemporaneo, 14 junho 2018.

87 Sobre tal questão ver U. VERONESI, Il diritto di morire. La libertà del laico di fronte alla sofferenza, Milano, Mondadori, 2006; C. TRIPODINA, Quale morte per gli "immersi in una notte senza fine"? Sulla legittimità costituzionale dell'aiuto al suicidio e sul "diritto a morire per mano d'altri", en Rivista di BioDiritto, 2018.
} 
à parte na qual o artigo 580 considera penalmente relevante a mera ajuda material ao suicídio;

c) não há contradição entre o artigo 580 do Código Penal e o artigo $8^{\circ}$ do $\mathrm{CEDH}$, que protege o direito de toda pessoa referente a sua vida privada e familiar. É certo que o TEDH declarou que a proibição, penalmente sancionada, de ajudar a outros ao suicídio pode constituir uma ingerência no direito em questão, mas também é certo que podem introduzir limitações ao tal direito justificadamente com a finalidade de "proteger os direitos e liberdades dos demais", especialmente no que se refere à proteção das pessoas mais debilitadas e vulneráveis. A Corte Constitucional considera, em essência, que a regulamentação das questões examinadas deve ser reconduzida à margem da apreciação dos Estados;

d) consequentemente, a incriminação da ajuda ao suicídio não pode ser considerada constitucionalmente ilegal.

Entretanto, a Corte Constitucional admite que exista um caso particular, pelo qual se pode introduzir um tratamento diferenciado, extraído do artigo $3^{\circ}$ da Constituição (Italiana), para o caso de uma pessoa que: (a) sofre uma patologia irreversível; (b) é submetido a sofrimento físico ou psicológico, que considera absolutamente intolerável; (c) mantém-se com vida mediante tratamentos de assistência vital; (d) é capaz de tomar decisões de maneira livre e consciente. Assim, em casos desse tipo, a assistência por parte de terceiros para pôr fim a sua própria vida se converte para o enfermo na única maneira possível de evitar uma vida artificial não desejada que tem direito a recusar em conformidade com o artigo 32 da Constituição, de acordo com seu próprio conceito subjetivo da própria dignidade.

Concretamente em relação a este caso específico, a Corte observa que:

a) a Lei 219/2017 reconhece o direito a recusar ou interromper qualquer tratamento de saúde, inclusive ainda que seja indispensável para a manutenção da vida, referindo-se expressamente à noção de "tratamento de saúde" para a hidratação e à alimentação artificiais. Entretanto, a norma vigente não permite ao médico, incluída a petição expressa do paciente neste sentido, administrar tratamentos dirigidos em não aliviar o sofrimento, senão a causar a morte (salvo em casos especiais e já mencionados relativos à chamada "terapia da dor" com referência aos enfermos terminais, para os quais em qualquer caso, como já foi dito, não se pode falar de eutanásia ativa);

b) à luz do marco anteriormente descrito, resulta que o paciente se vê materialmente obrigado a passar por um processo lento e doloroso para seus entes queridos, frequentemente incompatíveis com uma determinada visão da própria dignidade em relação com a vida e a morte; 
c) "a proibição absoluta de ajuda ao suicídio termina limitando a liberdade e autodeterminação do enfermo na escolha dos tratamentos, incluídas as destinadas a libertá-lo do sofrimento derivado dos artigos $2^{\circ}$ e 13 e do parágrafo segundo do artigo 32 da Constituição (Italiana), impondo uma única modalidade de se despedir da vida, sem que esta limitação possa ser considerada preestabelecida para a proteção de outros interesses constitucionalmente tuteláveis, com a consequente vulnerabilidade do princípio da dignidade humana, assim como os princípios de razoabilidade e igualdade atendendo as mais diversas condições subjetivas."

Entretanto, a Corte Constitucional (Italiana) não considerou que pudesse intervir diretamente para remediar a situação mediante a "mera expulsão do âmbito de aplicação da disposição penal para aqueles casos em que os que se concedem ajudas a pessoas cumprem as condições anteriormente descritas." De fato, tal solução havia criado um vazio jurídico no qual a Corte teme que podiam ser criados espaços que dessem lugar a formas de abusos.

Por conseguinte, a Corte Constitucional (Italiana) considerou que o que define como "ponderações delicadas", que necessariamente envolvem as questões relativas ao final da vida, corresponde inicialmente ao Parlamento, na sua qualidade de titular do poder legislativo, enquanto que a tarefa do Tribunal consiste em verificar ex post a constitucionalidade das decisões adotadas pelo Parlamento. A Corte Constitucional também afirma que a solução normal no tal caso deveria consistir na inadmissibilidade da questão de constitucionalidade elevada pelo tribunal nacional, advertindo ao legislador de que adotar as normas necessárias, posto que ao contrário, o pronunciamento de uma decisão de inconstitucionalidade não evitaria que tornasse a ser pleiteada no futuro, se o legislador não considere em si sua função.

Não obstante, "para evitar que a norma possa encontrar aqui uma aplicação, a médio prazo, deixando em todo caso ao Parlamento a possibilidade de adotar as decisões necessárias, que em princípio se deixam a sua discrição - sem prejuízo da necessidade de garantir a proteção do enfermo dentro dos limites estabelecidos por este pronunciamento", a Corte Constitucional (Italiana) considerou que "deveria fazê-lo de outra maneira, apoiando-se em suas competências para gerir o processo constitucional": ou seja, "ordenar o adiamento da sentença em curso, fixando uma nova discussão sobre as questões de legitimidade constitucional na audiência de 24 de setembro de 2019, ao fim da qual será possível avaliar a possível existência de uma lei que regule a matéria em conformidade com as necessidades de tutela indicadas." A Corte Constitucional especificou que, sem prejuízo da suspensão do procedimento principal,

nos demais procedimentos, corresponderá aos tribunais valorar se, à luz do indicado na presente sentença, questões similares de legitimidade constitucional da disposição em questão devem ser consideradas relevantes e não manifestamente infundadas, com a finalidade de evitar a aplicação parcial da mesma disposição no presente caso. 
A sentença examinada tem sido objeto de algumas críticas por parte da doutrina que a tem definido como "evasiva", 88 "passiva", ${ }^{89}$ concretamente como norma de "inconstitucionalidade diferida"..$^{90}$

De acordo com esta reconstrução, a Corte Constitucional elegeu deliberadamente um caminho de "inação", permitindo a superveniência de uma norma que ela mesma considerada inconstitucional (ainda que somente seja segundo a interpretação do juiz a quo e, por isso, do Direito vivo) para evitar uma invasão das competências legislativas do Parlamento, evitando assim a aparição de um novo choque sobre a usurpação (ou presumida usurpação) da função de produção normativa por parte dos juízes (um choque que, como ficou refletido, havia caracterizado precisamente os casos mais destacados do debate sobre o fim da vida).

Pelo contrário, outro setor doutrinário criticou uma "invasão de campo" por parte da Corte Constitucional (Italiana), que havia tentado "forçar a mão" do legislador, indicando um caminho muito preciso para o próximo exercício da discricionariedade política, um caminho considerado perigoso no sentido de que pretende legalizar, em última instância, as formas de suicídio assistido. ${ }^{91}$ Nestes termos, segundo a tese examinada, seria ilegítimo reduzir a margem de discricionariedade que ostenta o legislador pela mão da Corte, que substancialmente já havia eleito os valores nos quais posteriormente se embasaria o próximo exercício do poder legislativo.

Posto que, de antemão, no plano jurídico uma sentença interpretativa de rejeição, de aceitação, ou inclusive de manipulação, talvez tivesse sido mais apropriada. Entretanto, parece que a Corte não quis invadir o âmbito da discricionariedade política do legislador, especialmente na questão ética particularmente delicada. Por isso, adotou uma solução particularmente criativa, e tomando emprestado o instrumento da "advertência ao legislador" impondo-lhe um prazo para levar a cabo sua função, instrumento previsto em outros ordenamentos jurídicos europeus e ocidentais (por exemplo, Alemanha e Canadá) mas ainda desconhecido para a justiça constitucional italiana. ${ }^{92}$

Ademais cabe assinalar que a peculiar solução finalmente adotada pelo Tribunal talvez poderia ser sintomática de uma divisão interna em seu próprio seio ao tratar sobre a questão especialmente complexa e delicada desde o ponto de vista ético-moral, que não pode, como é compreensível deixar imunes nem mesmo os juízes constitucionais.

\footnotetext{
${ }^{88}$ Neste sentido A. RUGGERI, Pilato alla Consulta: decide di non decidere, per lo meno per ora... (a margine di un comunicato sul caso Cappato), en Consulta online, n. 3, 2018.

${ }^{89}$ Nesta linha se pronuncia U. ADAMO, La Corte è 'attendista'... "siriviéndose de sus intereses en la gestión del proceso constitucional». Nota de la Corte Const. ord. n. 207 del 2018, en Forum di Quaderni costituzionali, 23 novembro 2018.

${ }_{90}^{0}$ Neste sentido M. BIGNAMI, Il caso Cappato alla Corte costituzionale: un'ordinanza ad incostituzionalità differita, en Questione giustizia, 19 novembro 2018.

91 Sobre o temo ver G. RAZZANO, La Corte costituzionale sul caso Cappato: può un'ordinanza chiedere al Parlamento di legalizzare il suicidio assistito?, en Diritti fondamentali.it, n. 1, 2019.

${ }_{92}$ Ver, J. LUTHER, The judge's power over life and death, cit.; M. BIGNAMI, Il caso Cappato alla Corte costituzionale: un'ordinanza ad incostituzionalità differita, cit.
} 
Mas o que fará a Corte Constitucional se, tal como já parece extremamente provável, a data fixada para a Audiência o legislador não estiver pronto para reformar a matéria segundo os Princípios do Direito que lhe foram impostos? Em efeito parece difícil esperar que, no pouco tempo que falta antes de que vença o prazo indicado pela Corte, o Parlamento possa aprovar a proposta de lei de iniciativa popular na matéria (que atualmente está sendo examinada na Comissão na Câmara), ou ainda o projeto de lei sobre a mesma matéria apresentada no Senado (para o qual, entre outras coisas, o exame na Comissão todavia não começou).

Enfatizou-se que as distintas opções que provavelmente se coloquem sobre a mesa sejam quatro: uma declaração de inconstitucionalidade parcial do artigo (580) do Código Penal, na parte em que se estabelece a pena mínimo de 5 anos também para a ajuda ao suicídio; uma declaração de inconstitucionalidade parcial do artigo 580 do Código Penal, na medida em que equipara a mera facilitação à instigação ao suicídio; uma declaração de inconstitucionalidade parcial do artigo 580 do Código Penal na medida em que sanciona o suicídio assistido, inclusive se o ato final se realiza em um Estado em que tal prática é legal, uma declaração de inconstitucionalidade do artigo 580 do Código Penal, na medida em que já não respeita os princípios de igualdade, liberdade e razoabilidade, com a advertência ao Parlamento sobre uma nova regulamentação da matéria e do poder de suspensão das sentenças pendentes diante das autoridades judiciais (cujo exercício, entretanto, parece ser, neste caso, obrigatório). ${ }^{93}$

Apesar das compreensíveis críticas que foram feitas sobre o pronunciamento em questão, o certo é que, em uma conjuntura política e social na qual o circuito das decisões democráticas no âmbito da representação política está frequentemente deslegitimado pelo corpo social, ${ }^{94}$ há de se valorizar positivamente a eleição da Corte Constitucional de reforçar o papel do legislador e, por outro lado, de responsabilizar pela adoção de decisões públicas.

Por fim, resulta extremamente importante que o Paramento torne a se apropriar de seu papel central em relação a posições que sem dúvida podem ser complexas e divisórias desde as diferentes perspectivas, mas que, precisamente por esta razão, requerem um espaço irredutível a favor da reconciliação e o equilíbrio dos interesses constitucionais implicados no âmbito da discricionariedade política.

O papel "alternativo" e "residual" que a Corte Constitucional desenhou para si mesma no presente caso, lido a partir desta perspectiva, não parece carente de perfis apreciáveis de prudência e sensibilidade institucional.

\footnotetext{
93 Ver: J. LUTHER, The judge's power over life and death, cit., 14.

94 Sobre este tema permita o encaminhamento a P. BILANCIA, Crisi nella democrazia rappresentativa e aperture a nuove istanze di partecipazione democratica, en P. Bilancia (a cura di), Crisi della rappresentanza politica nella democrazia contemporanea, Torino, Giappichelli, 2018.
} 
